\title{
Proportional Swivel Headlight and Foglight Mechanism
}

\author{
Prit D Shah, Ajay M Patel, Manan Desai
}

Mechanical Engineering, GCET, Vallabh Vidyanagar, India

${ }^{*}$ Corresponding Author email: shahprit22@gmail.com

Article Histary

Received: 05 July 2018

Revised: 13 October 2018

Accepted: 25 November 2018

Published: 02 December 2018

Student(s)

- $\quad$ Prit D Shah

Academic Year: 2018-19
Course Level: Bachelor
Course Name: B.Tech. (Mechanical
Engineering)
Course year: $4^{\text {th }}$ Year

$\operatorname{Mentor}(\mathrm{s})$

- Ajay M Patel

- Manan C Desai

\section{ABSTRACT}

This paper describes the hardware of movable Headlight \& Foglight system for vehicles. It has been found that the majority of accidents take place due to the invisibility of road at night $\&$ in fog. So, it becomes necessary that we get a clear vision during the night \& in fog so as to avoid accidents. Therefore, the following research represents the rotation of headlight $\&$ foglight with the rotation of wheels. In this system used rack \& pinion arrangement which give the drive to the optical axes on which headlight $\&$ foglight are mounted so when the links are moved with steering arm that gives predefined motion to headlight and foglight. Hence the light from the Headlight \& Foglight focuses properly on the road, also while taking turn the driver coming from the opposite side can easily notice the upcoming vehicle $\&$ so the number of accidents is minimized. In this paper, we have defined a novel approach movement of foglight along with the headlight.

Keywords: Automotive Headlight system, automotive foglight system, Mechanism, Design.

\section{Introduction}

Presently, there are lots of research being done for moving headlight of vehicles through an angle, in left or right direction by rotation of steering. This increases the safety of vehicle while travelling at night time, especially when taking sharp turns. This research paper focuses on rotation of headlight as well as foglight through an angle, in left or right direction by rotation of steering. This increases the safety of vehicle while travelling at night time \& even in fog. Driver's visibility will increase at night \& in fog. We would be able to focus the beam of headlight $\&$ foglight in proper useful direction. There will be less number of accidents at night time \& in fog, while taking turn on sharp turning roads. This will be much more useful in hilly areas. Wang and Wu [1], suggested the control model and simulation for Adaptive Front light System (AFS) of vehicles on curve roads. Shreyas and Raghuraman [2] proposed a cost-effective technique to illuminate blind spots while driving in the night and during the times when the visibility is reduced significantly so as to make the objects visible in those darkened locations. F Guo et al [3] proposed use of newly developed adaptive front-lighting system based on CCD which was better than the traditional one. Jiang and Cheung [4] investigated the optical design, fabrication and the measurement of the freeform reflector headlamps. 
Vaishali and Bachute [5] made use of Adaptive Front Light System (AFS) for better illumination of light at night time on curved road, by making horizontal \& vertical movement of headlamp. Guo and Wang [6] developed an adaptive front-lighting system (AFS) of automobile controlled by STC12C5A60AD which is the core of electric control unit. Manish and Kushal [7] made use of camera as image sensor to detect and capture the details of the curved road ahead of the vehicle, as a result a suitable light beam with improved road illumination is obtained for the curved roads. Snehal et al [8] suggested that when driving on the curve road, Adaptive front light system (AFS) will change the lighting pattern to compensate for the curvature of the road to help enhance night visibility. Jitender and Kanika [9] proposed a method of turning headlight at an angle along with steering by using cam and follower, gearing and spring mechanism. Pankaj and Alok [10] developed a low cost method for turning headlight at an angle along with steering by utilizing a gear which is in mesh with a semicircular gear and motion is transmitted using linkages and wire mechanism. Yogesh and Chakradhar [11] developed a method for front wheel steering system with moveable headlights with latest electronics technology, here they have used ackermans principle. Ajay and Shivraj [12] developed a novel method of turning only on side headlight along with the steering and keeping the other side headlight steady, even their method is cost effective.

\section{Problem Description}

It is found from many surveys that majority of accidents take place at night $\&$ in fog, this is because of lack of clear vision to the drivers. At night $\&$ in fog while taking sharp turns as soon as the driver rotates the steering the wheels take a turn but the car body do not take the turn simultaneously, so there is a time delay between the wheels \& the car body. Hence the light do not focus on the turning path, so the driver cannot see the path as well as they cannot see the opposite vehicle coming towards them, which can lead to accident.

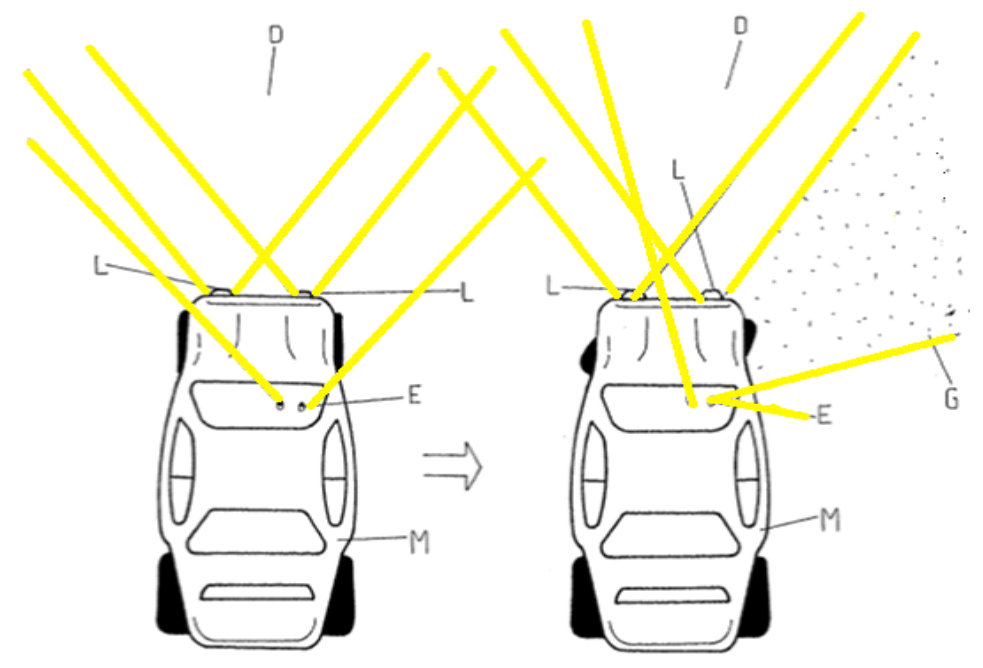

Figure 1: Projection of headlight automotive vehicle [13]

As seen in the figure 1, first the car is moving on a straight path \& then it has to take a right turn. So as seen in figure 1, that as the wheel rotates car body do not rotate $\&$ hence the headlight $\&$ the foglight cannot cover the turning path. So the driver cannot see the turning path \& can meet with the accident. The probability of such accidents increases in hilly regions where there are many sharp turns to be taken.

\section{Steering Mechanism}

Steering mechanism of any automobile is used to control the direction of motion of automobile. In 4 wheelers rotatory motion of steering is converted to angular motion of front wheels. This conversion takes place Rack and Pinion Steering Gear, in rack \& pinion mechanism the rotatory motion of pinion is transferred to linear motion of rack. In cars the steering is connected to the pinion. So as the steering is 
Shah et al., Adv. J. Grad. Res.; Vol. 5, Issue 1, pp: 55-60, January 2019

rotated the pinion rotates which in turns gives linear motion to the rack. As the rack is connected to the axel of the wheels, so due to the linear motion of rack the wheels are rotated $\&$ hence the car takes the turn.

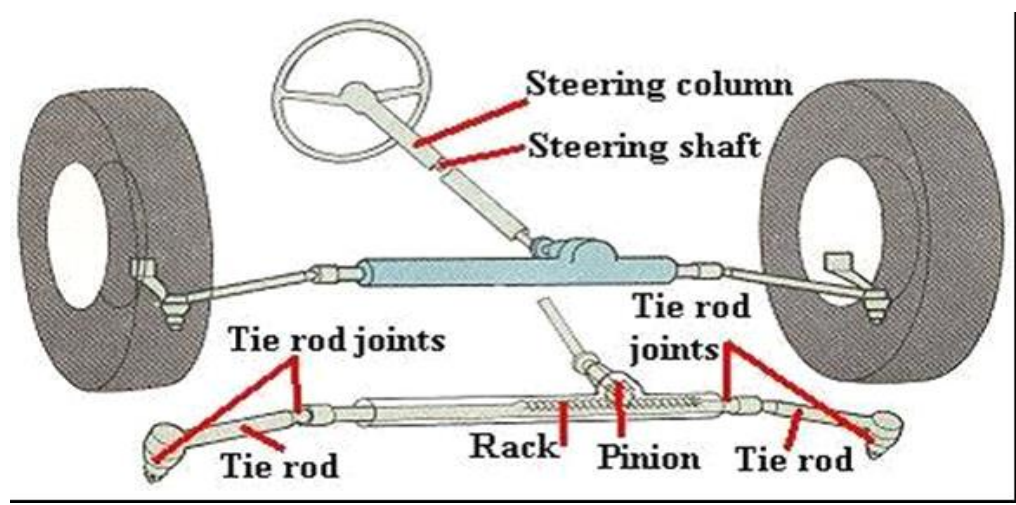

Figure 2: Rack \& Pinion [13]

Figure 2 shows Rack \& Pinion mechanism which is used as steering mechanism.

\section{Construction \& Working}

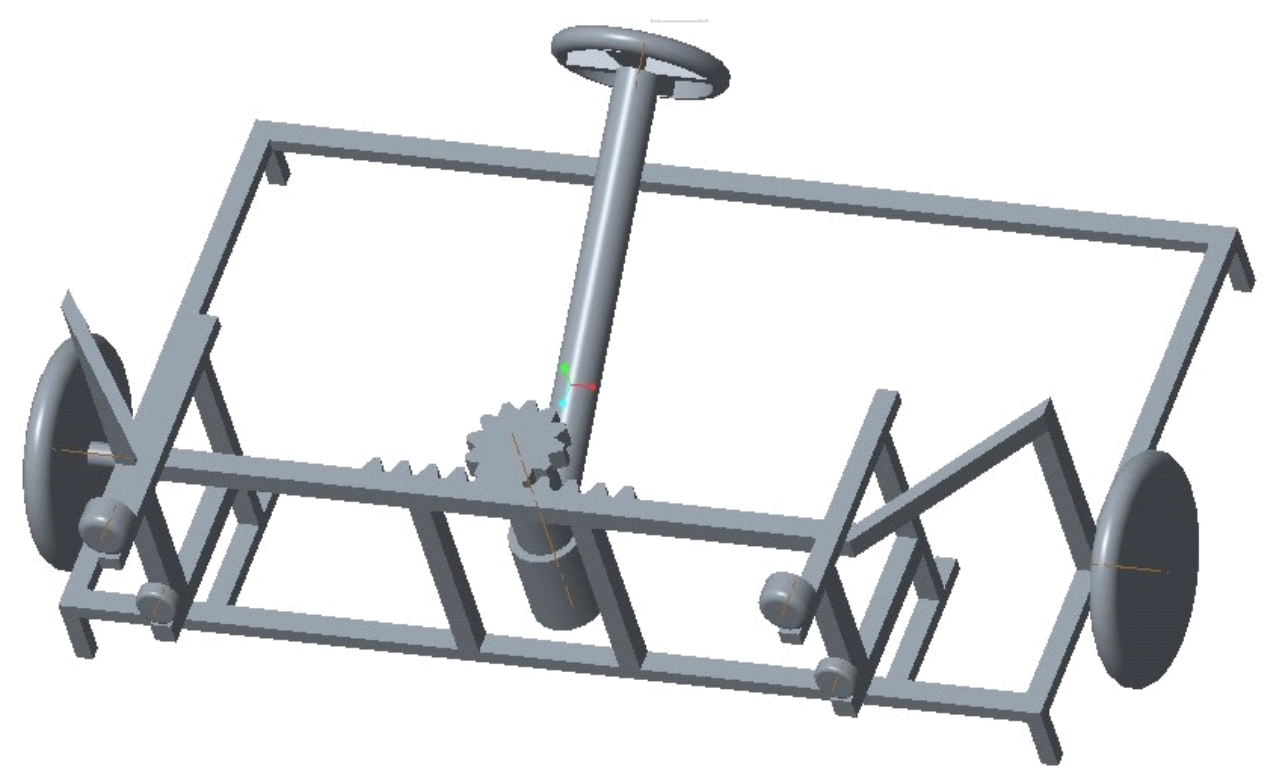

Figure 3: Movable Headlight \& Foglight with Steering System.

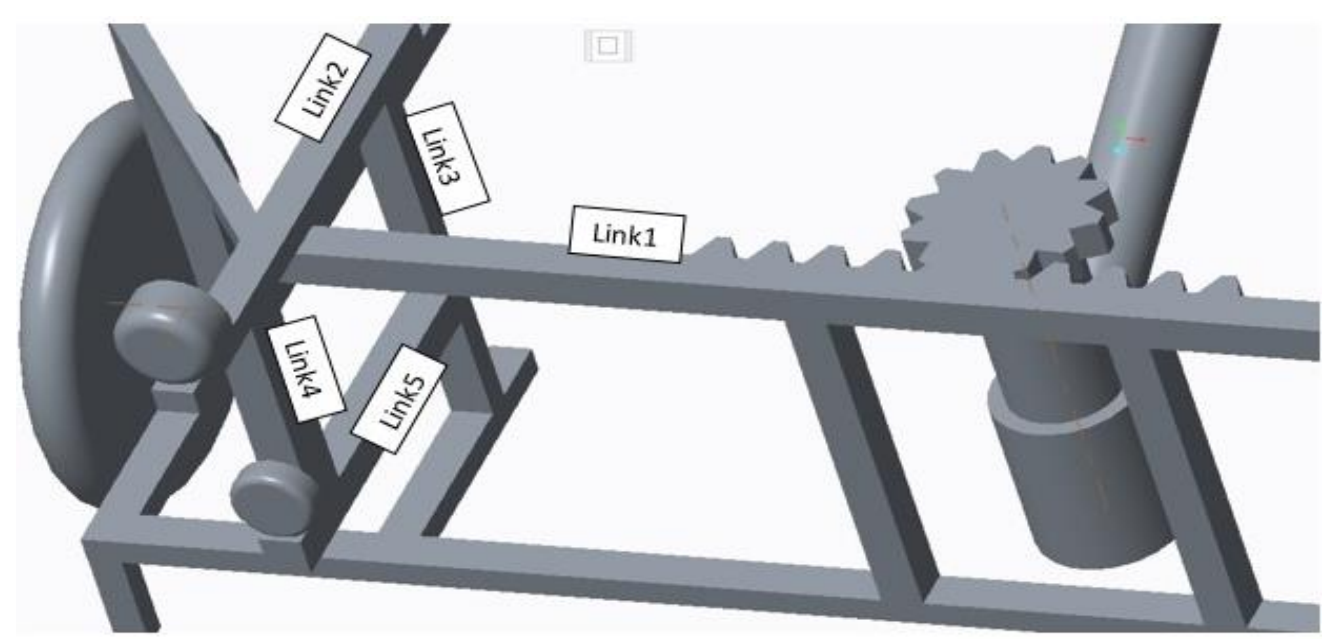

Figure 4: Movable Headlight \& Foglight with Steering System. 


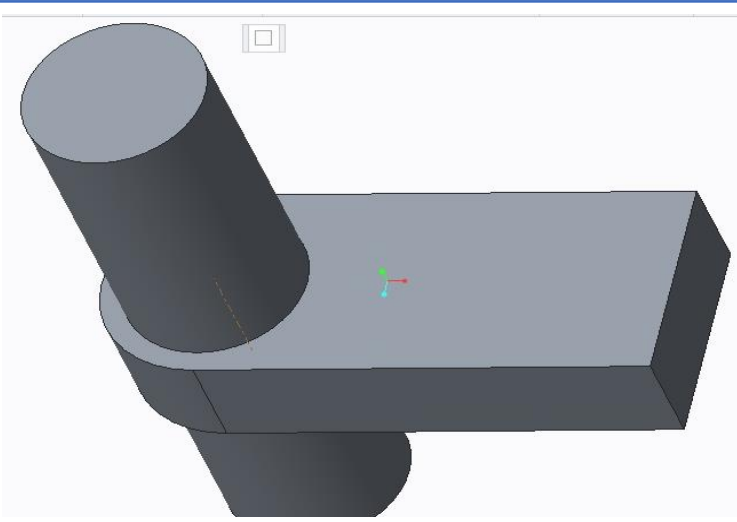

Figure 5: Hinge Joint

Here figure 3 shows the overall mechanism which rotates headlight \& foglight along with the rotation of wheels. Figure 4 shows a particular portion of figure 3 which makes it easy to understand the mechanism. Figure 5 shows the construction of hinge point which is present between link $3 \& \operatorname{link} 2$ and also between link3 \& link5 of figure 4.

As shown in figure 4 , here the rack \& pinion arrangement is use to rotate the wheel \& to take the turn. Here the pinion is connected with the steering so that with the rotation of steering the pinion gets rotated. There is a rack attached with the pinion. This rack is connected to the wheels of the vehicle. Now as we rotate the steering the pinion gets rotated with it which in turn pushes the rack to left or right direction. Due to this the wheels gets rotated $\&$ the vehicle takes the turn.

Here the headlight is connected to the link1 joining, the rack to the wheels of the vehicle with the help of a link1. The link2 carries headlight at one end \& on other hand it is attached with a link3 through a hinge joint (figure 5). The link3 is provided to connect the link 2 which carries headlight with the link5 which carries foglight $\&$ finally it is attached with the base. This link 3 is attached rigidly with the base. The link3 of headlight $\&$ the link 5 of foglight are attached to that link 3 with a hinge joint. The hinge joint is provided to allow rotation of headlight $\&$ foglight. Also, there is another link 4 which connects only headlight \& foglight. This link 4 is necessary to move foglight along with the headlight.

So, as soon as driver will rotate the steering the pinion will get rotated which in turn will push the rack in right or left direction. As the rack will move the link1 will get displace because of that the link 2 carrying the headlight will rotate about the hinge joint provided between link 2 \& link3. Hence, the headlight will rotate as the vehicle takes the turn. Also, the link 4 which connects link 2 of headlight $\&$ link 5 of foglight, will help to rotate the foglight along with the headlight about a hinge joint, which is provided between link $5 \&$ link 3 . So we can say that as the driver rotates the steering then along with the rotation of wheel even the headlight \& the foglight gets rotated through an angle. Hence the driver can get a clear vision while taking a sharp turn at night or in fog. So due to this number of accidents can be minimized to a great extent.

\section{Results \& Discussion}

In this manuscript the major advantage of this method is, it provides rotation of foglight along with the rotation of headlight, because of this the driver can get a clear vision at night as well as in fog. Also, here in the research paper we have describe our project based on rack and pinion steering mechanism, but this method can be used with majority of other steering mechanism [9], [10], [11], [12]. By providing few more links \& joints we can have rotation of foglight along with headlight hence it is a cost-efficient method. Hence this method is technically feasible. The only drawback of this method is that, here we have to provide some extra links \& joints which gives rotation of headlight \& foglight along with the rotation of wheels, this extra links \& joints increases the overall weight of the vehicle \& adds up some extra cost, but the increased weight $\&$ the increased cost are negligible compared to the overall weight $\&$ cost of the vehicle. Hence in such there is no disadvantage of this method. This method is useful only on curve roads \& not on straight roads. 
Shah et al., Adv. J. Grad. Res.; Vol. 5, Issue 1, pp: 55-60, January 2019

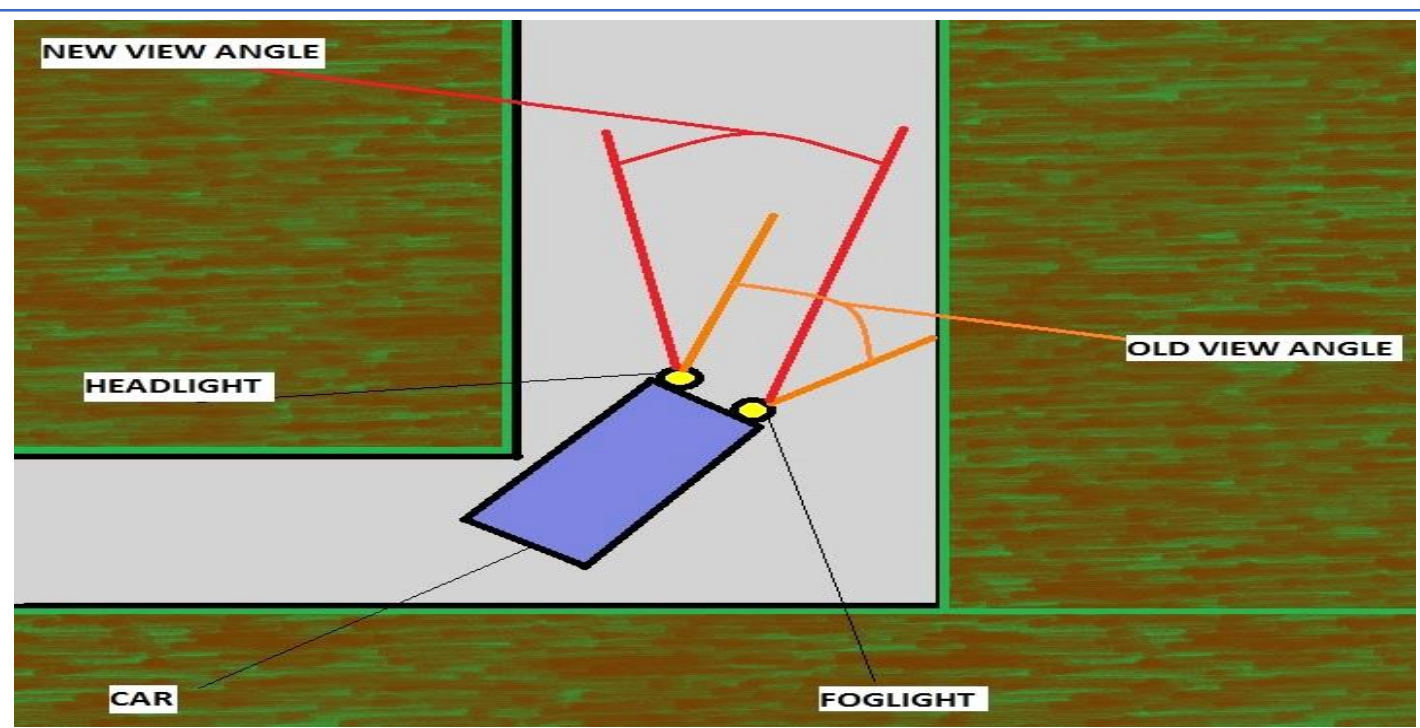

Figure 6: Explaining areas with and without modification view of angle in the car

As shown in the figure 6 , as the car takes a left turn the headlights \& the fog lights also take left turn \& so we get the new view angle. Hence the light from the Headlight \& Foglight focuses properly on the road, also while taking turn the driver coming from opposite side can easily notice the upcoming vehicle \& so the number of accidents is minimized.

Table 1: Automotive system data for left \& right side turn [13]

\begin{tabular}{|c|c|c|c|c|c|c|}
\hline $\begin{array}{l}\text { Angle of } \\
\text { turning of } \\
\text { steering } \\
\text { wheel } \\
\text { X\{degrees\} } \\
\text {-ve [left] } \\
+ \text { ve [right] }\end{array}$ & $\begin{array}{l}\text { Angle of } \\
\text { turning of } \\
\text { steering } \\
\text { wheel } \\
\text { Y\{degrees\} } \\
\text {-ve [left] } \\
+ \text { ve [right] }\end{array}$ & $\begin{array}{l}\text { Steering } \\
\text { Ratio } \\
(\mathrm{X} / \mathrm{Y})\end{array}$ & $\begin{array}{l}\text { Angle of } \\
\text { turning of } \\
\text { headlight on } \\
\text { left side } \\
\text { \{degrees\} } \\
\text {-ve [left] } \\
\text { +ve [right] }\end{array}$ & $\begin{array}{l}\text { Angle of } \\
\text { turning of } \\
\text { foglight on } \\
\text { left side } \\
\text { \{degrees } \\
\text {-ve [left] } \\
+ \text { ve [right] }\end{array}$ & $\begin{array}{l}\text { Angle of } \\
\text { turning of } \\
\text { headlight on } \\
\text { right side } \\
\text { \{degrees } \\
\text {-ve [left] } \\
\text { +ve [right] }\end{array}$ & $\begin{array}{l}\text { Angle of } \\
\text { turning of } \\
\text { foglight on } \\
\text { left side } \\
\text { \{degrees\} } \\
\text {-ve [left] } \\
\text { +ve [right] }\end{array}$ \\
\hline-200 & -11 & 18.18 & -8 & -6 & -5 & -3 \\
\hline-400 & -22 & 18.18 & -16 & -13 & -10 & -8 \\
\hline-600 & -33 & 18.18 & -25 & -21 & -15 & -13 \\
\hline 0 & 0 & & 0 & 0 & 0 & 0 \\
\hline 200 & 11 & 18.18 & 5 & 3 & 8 & 6 \\
\hline 400 & 22 & 18.18 & 10 & 8 & 16 & 13 \\
\hline 600 & 33 & 18.18 & 15 & 13 & 25 & 21 \\
\hline
\end{tabular}

Table 1 shows the degree of turning headlight \& foglight in left or right direction due to turning of steering wheel in left or right direction. It is clearly observed that angle of turning of steering wheel is increase angle of turning headlight and fog light is increase.

\section{Conclusion}

As the 4-wheeler takes a turn the headlights \& the foglights also takes a turn along with the vehicle. Hence by adapting this mechanism we can reduce the number of accidents taking place at night $\&$ in fog, due to sharp turnings especially in hilly regions. It is also a cost-efficient method. So, this method can be implemented in all 4 wheelers. 


\section{How to Cite this Article:}

P. Shah, A. Patel, and M. Desai, "Proportional Swivel Headlight and Foglight Mechanism", Adv. J. Grad. Res., vol. 5, no. 1, pp. 55-60, Dec. 2018. Doi: 10.21467/ajgr.5.1.55-60

\section{References}

[1] Weifeng Wang, Qing Wu, "Control Model and Simulation for Adaptive Front light System of Vehicle on Curve Roads" 2008 IEEE Vehicle Power and Propulsion Conference, 2010.

[2] Shreyas S; Kirthanaa Raghuraman, "Adaptive Headlight System for accident prevention", 2014 International Conference on Recent Trends in Information Technology.

[3] Fengqun Guo, Hui Xiao; Shouzhi Tang, "Research of Modeling and Simulation on Adaptive Front-Lighting System for Corner Based on CCD" 25th Chinese Control and Decision Conference (CCDC) IEEE, (2013).

[4] J.B. Jiang, C.F. Cheung, S, "Design and fabrication of freeform reflector for automotive headlamp" 2nd International Conference on Power Electronics Systems and Applications: Hong Kong, p: 220-224, 12-14 November (2006).

[5] Vaishali D.Todkar, Mrs.M.R.Bachute, "Adaptive Front Light System", International Journal of Advanced Research (2016), Volume 4, Issue 5, pp:907-913.

[6] Guo Dong ; Wang Hongpei ; et al, "Study on adaptive front-lighting system of automobile based on microcontroller", Proceedings 2011 International Conference on Transportation, Mechanical, and Electrical Engineering (TMEE).

[7] Manish Bonde; Kushal Sakure; et al, "Adaptive Front Light System Using ARM", International Journal of Informative \& Futuristic Research (IJIFR), Volume 2, Issue 7, pp: 2296- 2302.

[8] Sneh Parhad, "Development of Automotive Adaptive Front Lighting System," Proceedings of IRF International Conference, ISBN: 978-93-82702-56-6, 5th \& 6th February (2014), Pune India

[9] Jitender Malik; Kanika Booria, "Design of mechanical components of Steering controlled headlights". Project Report

[10] Singh, P., Taneja, N., Sharma, A., and Gaurav, A., "Development of an Adaptive Steering Controlled Headlight for Low Cost Vehicles," SAE Technical Paper 2016-28-0174, 2016.

[11] Gadhave Yogesh V; Jadhav Chakradhar R; et al "Front Wheel Steering System with Movable Headlights" Vol-3 Issue-2. IJARIIEISSN(O)-2395-4396, 2017.

[12] Ajay R. Pawar; Shivraj S. Salekar; et al, "Design and Fabrication of Movable Headlight System". International Journal of Advance Engineering and Research Development, Volume 4, Issue 5, May -2017.

[13] Manisha V Makwana; Akshay Shah; et al, "Design and Manufacture of Movable Headlight System in Automobile", International Journal of Innovative and Emerging Research in Engineering, vol 1, issue 2, pp 12-16, February 2014.

Publish your research article in AIJR journals-

$\checkmark \quad$ Online Submission and Tracking

$\checkmark$ Peer-Reviewed

$\checkmark \quad$ Rapid decision

$\checkmark \quad$ Immediate Publication after acceptance

$\checkmark \quad$ Articles freely available online

$\checkmark \quad$ Retain full copyright of your article.

Submit your article at journals.aijr.in
Publish your books with AIJR publisher-

$\checkmark \quad$ Publish with ISBN and DOI.

$\checkmark \quad$ Publish Thesis/Dissertation as Monograph.

$\checkmark$ Publish Book Monograph.

$\checkmark$ Publish Edited Volume/ Book.

$\checkmark \quad$ Publish Conference Proceedings

$\checkmark \quad$ Retain full copyright of your books.

Submit your manuscript at books.aijr.org 